Adolescents' preferences regarding

\title{
sex and relationship education
}

Triece Turnbull, Paul van Schaik and Anna van Wersch 


\section{Abstract (word count: 228)}

Purpose: There is a lack of research on adolescent's preferences for Sex and Relationship Education (SRE) and predictors of these preferences. The aim of the current study was to examine adolescents' perceptions of the quality of an SRE intervention, their preferences for sources of SRE and how these vary as a function of gender, school's faith and school type.

Methods: The participants $(\mathrm{N}=759$ adolescent girls $(57 \%)$ and boys $(43 \%))$, who had attended an SRE intervention and had previously been given formal SRE within the school they attended, completed a survey on their preference for aspects of SRE.

Results: Adolescents judged the sex-education intervention to be of high quality and enjoyed being taught by sexual-health workers. Preferred sources of SRE included sexual-health workers, parents and peers as well as the media. Logistic regression analysis demonstrated that gender, school's faith (Church of England or catholic) and school type (mainstream, special needs) were predictors of preference for various aspects of SRE.

Conclusion: The results highlight the crucial role of experienced qualified SRE educators, but also the supplementary role of parents and peers as well as the auxiliary role of Internet sites, magazines, phone lines and schools. Stereotypical preferences of boys and girls outside SRE seem to be perpetuated in SRE and special-needs and mainstream adolescents' preferences are consistent with their communication and education outside SRE.

Key words: sex education, gender, media, peers. 


\section{Word count of main text: 3,167 (maximum 3,500 )}

\section{Introduction}

The importance of effective sex and relationships education (SRE) has been well documented, especially since 2000 when the Department for Education and Employment (DfEE, 2000) provided legislation ('Sex and Relationship Guidance' (2000)) to support primary and secondary schools with guidance detailing the most effective methods to teach SRE. The legislation is recognised and regarded by the government department; Office for Standards in Education (OfSTED) as a tool promoting good practice. The SRE guidance highlights the importance of SRE and gives schools the foundations to teach effective SRE, especially by emphasising the important role of parents. According to research by Blake and Katrak (2002) and more recently Lynch and Blake (2004), it is imperative that schools work with parents/carers to provide a unified approach when teaching SRE and other sensitive issues to adolescents. This requirement is supported by Novilla, Barnes, La Cruz, Williams et al (2006) and Pike (2006) who have found that parents can play a central role in the development, growth and health of their children, especially in relation to information that helps their children form attitudes, beliefs and values about identity, relationships and intimacy.

For decades parents have expressed support for comprehensive SRE programmes that include instruction on abstinence, condoms and other methods of contraception (Weaver, Byers, Sears, Cohen et al (2002). There has been very little support by parents for abstinence-only programmes as they have often not been found to be effective in reducing sexual behaviour among adolescents (Anonymous, 2006; Bleakley, Hennessay \& Fishbein, 2006). Nevertheless, some faiths, such as Roman 
Catholic, Hindu and Jewish, do not permit the use of contraception and teaching contraception and how it can be accessed. These faiths also forbid homosexual behaviour and the teaching of it (Blake \& Katrak, 2002; Thomas, 1993). However, these religious beliefs have been challenged. It has been argued by Klein (2006) that by not teaching about all aspects of sex (e.g. sexual expression, love and lust) adolescents are being denied not just the right to discover who they are as individuals, but also to make informed decisions about their sexual behaviour and choices. Klein states that it is unacceptable for religious groups to be fanatic and forceful about their strict beliefs as it contradicts the sexually driven society that adolescents are familiar with. Further support for this argument has come from Rose (2005) who suggests that religion attempts to censor vital sexual information and information about services available to adolescents, which as individuals they have a right to know.

If parents or carers do not agree with the content of SRE then they can exercise their right to remove their children from SRE lessons (Blake \& Katrak, 2002). It is important though that when teaching SRE in a multi-cultural society, like Britain, schools are aware of cultural and religious beliefs adolescents may have from the family in which they have been brought up. This approach is reinforced in the National Curriculum and the DfEE SRE guidance (DfEE, 2000, p. 7), which - citing the Qualification and Curriculum Authority/DfEE (1999) - clearly states: "education is a route to spiritual, social, cultural, physical and moral development, and hence the well-being of the individual". To support schools further in teaching SRE the SRE guidance (DfEE, 2000) indicates how schools should deliver effective SRE programmes. SRE should be firmly rooted within the framework for Personal, Social and Health Education (PSHE) within the school curriculum. This allows schools to 
combine personal, social and health topics that include aspects of SRE. Although the SRE guidance recommends schools should have particular tutors to teach SRE, they are also encouraged to use outside agencies that have specialist training of SRE to assist in delivering effective SRE to adolescents (DfEE, 2000).

It is not only important to design and deliver appropriate SRE programmes, but also to provide sources of information that meet adolescents' preferences in order to enhance the effectiveness of SRE. Previous research has shown gender differences in preference for sources of information to learn and communicate in various domains. Teenage boys prefer the use of computers (Rautopuro et al. 2005) to learn about sexual matters, whereas men prefer mass and small media materials (Wolitski et al. 1996). However, computer use through the Internet provides online access to pornography (Haggstrom-Nordin, Sandberg, Hanson \& Tyden, 2006) and this use promotes the notion of women as sex objects (Jochen \& Valkenberg, 2007). What is surprising is that teenage girls and young women are now also starting to also learn about sexual matters and the opposite sex from computers (Subrahmanyam, Smahel \& Greenfield, 2006). This computer use is additional to female adolescents' traditional preferences of learning from teenage magazines, which boys are now also using to learn about sexual matters (Nonoyama, Tsurugi, Shirai, Ishikawa, \& Horiguchi, 2005; Taylor, 2005). Although the use of media by both teenage boys and girls is widening, different terminology is used in that magazines for girls use emotional words, whereas in teenage boy's magazines tough, macho cool words are used when referring to sexual content and behaviours (Willemson, 1998; Kim \& Ward, 2004; Baker, 2005; Peter \& Valkenberg, 2006). However, there is some evidence to suggest gender differences may occur when learning about sexual matters via computers and some research makes gender 
differences in preference for sources of SRE plausible (Willemson, 1998; Kim \& Ward, 2004; Baker, 2005; Peter \& Valkenburg, 2006).

Hypothesis 1: girls prefer human communication and media associated with human communication - such as magazines, but boys prefer technology as a source for SRE.

Although SRE is compulsory and should be taught following the SRE guidelines of the DfEE (2001), schools and their governors are responsible for deciding how SRE is to be delivered in individual schools. However, schools may differ in the quality and quantity of SRE they teach. As stated before, catholic schools generally adopt an abstinence-only approach, which does not encourage the use of or access to contraception (Thomas, 1993; Blake \& Katrak, 2002). This has been reflected in our research in that adolescents from catholic schools were more likely to choose alternative methods rather than 'school' to learn about aspects of SRE as they were not given this education from the school they attended. Furthermore, another characteristic of catholic education is a stronger reliance on (a single) authority, which follows from the more hierarchical and less democratic religious organisation of the catholic church than that of Church of England.

Hypothesis 2: adolescents from catholic schools prefer figures of authority more and have a stronger need for SRE as a relatively neglected subject that is not favoured by catholic 'ideology' than adolescents from non-catholic schools.

Adolescents who attend special schools vary in terms of type of disability, which can not only affect their physical functioning, but also their mental ability to understand and process information. It is therefore essential that SRE information is tailored to 
their needs when teaching the adolescents (Doyle, 2006), who generally rely on and interact more with parents or carers and on professionals than their peers.

Hypothesis 3: pupils from special-needs schools prefer parents, home and professionals as sources of SRE, but pupils from mainstream schools prefer a wider range of sources.

The aim of the current study was to examine adolescents' perceptions of the quality of an SRE intervention, their preferences for sources of SRE and how these vary as a function of gender, school's faith and school type as stated in the hypotheses.

\section{Method}

\section{Setting}

Eight community comprehensive schools took part in sex-education intervention. All were located in socio-economically deprived areas of the North East of England where educational attainment was low, teenage pregnancies were high and sexually transmitted infections continue to rise in adolescents (HPA/APHO, 2006). The schools sought consent from parents allowing their children to take part in the research. All of the adolescents who took part in the research were from Year 9 and would have received formal SRE in a classroom setting before attending the SRE intervention.

\section{Sex-education Intervention}

The sex-education intervention aimed to equip adolescents with the knowledge to make informed choices about their behaviour at an age where there is peer pressure and societal pressures to conform in the transition from childhood to adulthood. The objective of the sex-education intervention was to give adolescents in year 9 (age 
13-14 year) the opportunity to ask questions from experienced sexual health workers and participate in group discussions concerning a whole range of issues relating to human sexuality. The main topics covered within the sex-education intervention were puberty, body parts, myths and misconceptions, contraception, sexually transmitted infections and factual discussions on sex and sexual relationships, all of which were facilitated by sexual health workers rather than school teachers. Although main topics for discussion had been planned, adolescents were free to ask further questions and contact the sexual health workers at a later time if they had any problems or further questions. The sex-education intervention lasted no longer than an hour for each class of pupils (about 30 in each class). Because the sexeducation event was held in addition to any SRE given by each participating school, parental consent was sought by each school before the sex-education intervention was delivered.

\section{Participants}

Seven hundred and fifty-nine adolescents (432 girls (57\%) - and 327 boys (43\%)) aged 13 to 14 years took part in this study. Four hundred and ten were from three Church of England (C of E) schools (196 girls and 214 boys), 291 were from two catholic schools (211 girls and 80 boys) and 58 were from three special schools (25 girls and 33 boys).

\section{Questionnaire}

The six-item multi-choice questionnaire was designed to identify (a) who adolescents prefer to talk to about sexual matters, (b) the ways in which adolescents prefer to be taught SRE and (c) the sources that adolescents prefer to access as a means of learning more about sexual matters. In addition, questions were asked about 
respondents' gender swell as quantity, of and, enjoyment from the intervention. The questionnaire listed various sources of SRE and asked respondents to select those that they preferred.

\section{Data analysis}

Frequency analysis was carried out. In order to identify predictors of preference, logistic regression analysis was conducted with gender (male, female), faith of school (C of E, catholic) and type of school (mainstream, special needs) as predictors and aspects of preference for sources of SRE (being able to talk to, being taught by or receiving further information from a source) as outcomes.

\section{Results}

\section{All schools}

A majority of respondents judged the sex-education intervention to be very good $(\mathrm{N}=$ $389,51 \%)$ while most of the others judged it to be good $(\mathrm{N}=277,36 \%)$ and a very large majority enjoyed being taught by sexual-health workers $(N=722,95 \%)$. Overall, more than half of respondents felt they could talk about sex and relationships matters to their parents and friends (see Table 1). Just under half felt they could talk to a doctor (see Table 1 ), just under $40 \%$ to school nurses and just under that $15 \%$ to teachers. More than $60 \%$ of respondents preferred to be taught by sexual-health workers. Others (adolescents, school nurses, parents and teachers) were much less preferred. Close to half of respondents preferred Web sites as a source of further information, followed by magazines, phone lines and school (more than 30\%). Drop-in centre and home were less preferred (just over $20 \%$ ) and youth club and leisure centre were least preferred (less than 10\%). 


\section{Mainstream schools}

Gender and school's faith were investigated as predictors of preference for sources of SRE. There were statistically significant gender differences in preference for the following sources in order of effect size: friends (ability to talk to), Web sites, magazines (both preferences for more information), doctor (ability to talk to) and sexual-health workers (preference for being taught) (see Table 2). More girls than boys found they could talk to friends, but more boys than girls found they could talk to a doctor. For more information, more boys than girls preferred Web sites, but more girls than boys preferred magazines. More girls than boys preferred sexualhealth workers as teachers.

There were statistically significant differences between $C$ of $E$ and catholic schools in preference for the following sources in order of effect size: sexual-health workers (preference for being taught), perceived quality of SRE intervention, adolescents (preference for being taught), Web sites (preference for more information) and doctor (ability to talk to) (see Table 3). More respondents from catholic schools than from the $\mathrm{C}$ of $\mathrm{E}$ schools found the SRE intervention very good. More Catholics than Anglicans preferred sexual-health workers, but more Anglicans than Catholics preferred adolescents as teachers. More Anglicans than Catholics preferred websites for more information. More Catholics than Anglicans felt they could talk to a doctor.

Moderator effects of school type on the effect of gender or vice versa were investigated using logistic regression analyses on preference for sources of SRE. For Web sites, school was a significant moderator, $\chi^{2}(1)=4.55, p=0.03$. Tests of simple effects showed that gender was a significant predictor for $C$ of $E$ schools, $\chi^{2}(1)=8.94, p=0.003$ (56\% of boys and $41 \%$ of girls preferred Web sites), but an 
even stronger predictor for catholic schools, $\chi^{2}(1)=24.08, p<0.001(63 \%$ of boys and $31 \%$ of girls preferred Web sites). For magazines too, school was a significant moderator, $\chi^{2}(1)=5.31, p=0.02$. Tests of simple effects showed that gender was a significant predictor for C of E schools, $\chi^{2}(1)=17.85, p<0.001(42 \%$ of girls and $23 \%$ of boys preferred magazines), but not for catholic schools, $\chi^{2}(1)<1(37 \%$ of girls and $35 \%$ of boys preferred magazines).

\section{Special schools}

There were statistically significant gender differences in preference for the following sources in order of effect size: Web sites, phone line (both preference for more information) and friends (ability to talk to) (see Table 4). More boys than girls preferred Web sites, but more girls than boys preferred a phone line for more information. More girls than boys found they could talk to friends.

\section{Mainstream versus special schools}

There were statistically significant differences in preference for the following sources in order of effect size: sexual-health workers, parents (both preference for being taught), friends (ability to talk to), home (preference for more information), school nurse (preference for being taught) and magazines (preference for more information) (see Table 5). More mainstream than special-needs respondents preferred sexualhealth workers, but more special-needs respondents preferred parents and a school nurse as teachers. More mainstream than special-needs respondents found they could talk to friends. More special-needs than mainstream respondents preferred home for more information, but more mainstream than special-needs respondents preferred magazines. There were no significant moderator effects. 


\section{Discussion}

Adolescents judged the SRE intervention to be of high quality and enjoyed being taught by sexual-health workers. Mainstream-school pupils' preference for sources of information shows that sexual-health workers were the most preferred teachers of SRE. Parents and friends were most seen as people whom adolescents themselves could talk to. Web sites were the most popular source of further information, followed by magazines, phone line and school. These results demonstrate the crucial role of experienced professional teachers of SRE, but also the supplementary role of parents and peers as well as the auxiliary role of Web sites, magazines, phone lines and schools. The findings indicate that parents are seen as a source of communication rather than of education and teachers as a source of neither.

Hypothesis 1 - For SRE, girls in mainstream schools preferred friends, magazines and sexual-health workers more than boys, but boys preferred Web sites and doctors more for SRE. Furthermore, girls in special-needs schools preferred phone lines and friends more than boys, but boys preferred Web sites more. These results confirm girls' stronger interest in (informal) communication and in magazines as a source of information (Buston \& White, 2002; Walsh-Childers, Gotthoffer \& Lepre, 2002) as well as boys' stronger interest in technology as a source of information (Rautopuro et al. 2005). Therefore, stereotypical preferences of boys and girls in other domains seem to be perpetuated in SRE.

Hypothesis 2 - Pupils from catholic schools preferred sexual-health workers and doctors more and valued the SRE intervention more than pupils from $C$ of $E$ schools, but pupils from $\mathrm{C}$ of $\mathrm{E}$ schools had a stronger preference for adolescents and websites. These results confirm catholic schools' emphasis on figures of authority for 
information and suggest a greater need for and therefore, more appreciation of SRE in pupils in catholic schools, which until now appears to be more limited in these schools. The results also suggest that figures of authority are less emphasised in $\mathrm{C}$ of $E$ schools as a source of information. Gender was a stronger predictor of preference for Web sites for pupils in catholic schools than those in C of E schools. Gender was a significant predictor of preference for magazines in C of E schools, but not in catholic schools. Both of these results may reflect a stronger emphasis in catholic education on authority and the use of sources of authority (Rose, 2005; Klein, 2006).

Hypothesis 3 - Pupils from mainstream schools preferred sexual-health workers, friends and magazines more than pupils from special-needs schools, but pupils from special-needs schools had a stronger preference for parents, home and school nurses. These results reflect communication and education in other aspects of life in pupils from the different types of school: special-needs children are to more dependent on their parents, their home environment and professionals than other children (Doyle, 2006), who are more independent and interact with more types of people and to a larger extent gather information themselves from different sources. In sum, special needs pupils' and mainstream pupils' preferences regarding SRE are consistent with communication and education in other aspects of their life.

Based on the results of the current study, the following recommendations are important for the designing and delivery of effective SRE. When followed, these recommendations should result in better informed adolescents and a reduction of the problems, such as sexually transmitted diseases and teenage pregnancies, associated with a lack of SRE. Regarding gender, the different sources of additional information should be highlighted to both boys and girls to emphasise the range of 
sources for adolescents to consider rather than just the ones that they would have considered in any case. Regarding schools, all schools should make sure they provide sufficient SRE and highlight additional sources of SRE (DfEE, 2000). Regarding adolescents needs, for pupils attending mainstream and special-needs schools, pupils' preference for sources of SRE should be taken into account. For special-needs pupils, the role of parents or carers and health that of professionals should be emphasised, but for mainstream pupils the role of sexual-health professionals should be emphasised.

In conclusion, the problems of sexually transmitted diseases and teenage pregnancy indicate that that SRE still has not achieved its potential. This paper has identified adolescents' preferences for SRE and associations with gender, school type and adolescents' needs that should be taken into account in the designing and delivery of SRE. 


\section{References}

Anonymous. (2006). Abstinence-only education policies and programs: A position paper of the society for adolescent medicine. Journal of Adolescent Health, 38, 8387.

Baker, C.N. (2005). Images of women's sexuality in advertisements: A content analysis of black and white-orientated women's and men's magazines. Sex Roles, 52(1/2), 13-2.

Blake, S. \& Katrak, Z. (2002). Faith, Values and Sex \& Relationship education. London: National Children's Bureau.

Bleakley, A., Hennessay, M. \& Fishbein, M. (2006). Public opinion on sex education in sex education. Archive of Paediatric Medicine, 160, 1151-1156.

Buston, K. \& Wight, D. (2002). The salience and utility of school sex education to young women. Sex Education, 2(3), 233-250.

Department of Education and Employment. (2000). Sex and Relationship Education Guidance (1006/2000). HMSO.

Haggstrom-Nordin, E., Sandberg, J., Hanson, U \& Tyden, T. (2006). 'It's everywhere!!' Young Swedish peoples thoughts and reflections about pornography. Scandinavian Journal of Caring Sciences, 20(4), 386-393.

Jochen, P. \& Valkenberg, P.M. (2007). Adolescents' exposure to a sexualized media and their notions of women as sex objects. Sex Roles, 5(5-6), 381-395.

Kim, J.L. \& Ward, M. (2004). Pleasure reading: Associations between young women's sexual attitudes and their reading of contemporary women's magazines. Psychology of Women's Quarterly, 28, 48-56. 
Klein, M. (2006). America's War on Sex: The Attack on Law, Lust and Liberty. United States: Praeger Publishers/Greenwood Publishing Group. Pp. 212.

Lynch, J. \& Blake, S. (2004). Sex, Alcohol and Other Drugs. London: National Children's Bureau. Pp. 35.

Nonoyama, M., Tsurugi, Y., Shirai, C., Ishikawa, Y. \& Horiguchi, M. (2005). Influences of sex-related information for STD prevention. Journal of Adolescent Health, 36(5), 442-445.

Novilla, L.B., Barnes, M.D., De La Cruz, N.G., Williams, P.N. \& Rogers, J. (2006). Public health perspectives on the family: An ecological approach to promoting health in the family and community. Family \& Community Health, 29(1), 28-42.

Peter, J. \& Valkenburg, P.M. (2006). Adolescents' exposure to sexually explicit material on the Internet. Communication Research, 33(2), 178-204.

Pike, A. (2006). Family Relationships in Middle Childhood. London, National Children's Bureau.

Qualification and Curriculum Authority/Department of Education and Employment. (1999). National Curriculum Handbook for Secondary School Teachers. QCA/DfEE.

Rautopuro, J., Atjonen, P., Puurtinen, S. \& Pyykkonen, P. (2005). Students' selection between virtual and traditional exam: factors explaining the preferences to choose the study mode. Paper presented at the European Conference on Educational Research, University College Dublin, 7-10 September 2005, pp. 8. Retrieved from the World Wide Web, 20/11/2007: http://www.leeds.ac.uk/educol/documents/143172.htm

Rose, S. (2005). Going too far? Sex, sin and social policy. Social Forces, 84(2), $1207-1232$. 
Subrahmanyam, K., Smahel, D. \& Greenfield, P. (2006). Connecting developmental constructions to the Internet: Identity presentation and sexual exploration in online teen chat rooms. Developmental Psychology, 42(3), 395-406.

Taylor, L.D. (2005). All for him: Articles about sex in American Lad magazines. Sex Roles, 52(3/4), 153-163.

Thomas, R. (1993). Religion, Ethnicity \& Sex Education: Exploring the Issues. London: National Children's Bureau. Pp. 73-79.

Walsh-Childers, K., Gotthoffer, A. \& Lepre, C.R. (2002). From "Just the Facts" to “Downright Salacious": Teens' and Women's Magazine Coverage of Sex and Sexual Health. United States: Lawrence Erlbaum Associates Publishers. Pp. 308.

Weaver, A.D., Byers, S.A., Sears, H.A., Cohen, J.N. \& Randall, H.E.S. (2002). Sexual health education at school and at home: Attitudes and experiences of new Brunswisk parents. The Canadian Journal of Human Sexuality, 11(1), 19- 31.

Willemson, T.M. (1998). Widening the gender gap: Teenage magazines for girls and boys. Sex Roles, 38(9-10), 851-861.

Wolitski, R.J., Fishbein, M., Johnson, W.D., Schnell, D.J. \& Esacove, A. (1996). Sources of HIV information among injecting drug users: Association with gender, ethnicity, and risk behaviour. AIDS Care, 8(5): 541-555. 
Table 1. Preference for sources of sex- and relationship education (all schools)

\begin{tabular}{lc}
\hline Ability to talk to & \\
Parents & 55 \\
Friends & 54 \\
Doctor & 48 \\
School nurse & 38 \\
Teacher & 13 \\
\hline Preference for being taught & \\
Sexual-health worker & 63 \\
Adolescents & 21 \\
School nurse & 17 \\
Parents & 15 \\
Teacher & 9 \\
Preference for more information & \\
Web site & 45 \\
Magazines & 33 \\
Phone line & 31 \\
School & 31 \\
Drop-in centre & 23 \\
Home & 22 \\
Youth club & 8 \\
Leisure centre & 8
\end{tabular}

Note. Figures represent percentage of responses. 
Table 2. Logistic regression analysis of preference for sources with gender as a predictor (mainstream schools)

\begin{tabular}{lrrrrrrrr}
\hline & \multicolumn{3}{c}{ Percentage } & & & & \multicolumn{2}{c}{$\mathrm{Cl} .95$} \\
\cline { 2 - 5 } \cline { 7 - 9 } Source & Girls & Boys & $\chi^{2}(1)$ & \multicolumn{1}{c}{$\mathrm{p}$} & OR & $\mathrm{LL}$ & $\mathrm{UL}$ \\
\hline Friends $^{\mathrm{a}}$ & 68 & 40 & 55.51 & $<0.001$ & 3.21 & 2.35 & 4.40 \\
Web site $^{\mathrm{b}}$ & 36 & 58 & 33.36 & $<0.001$ & 0.41 & 0.30 & 0.55 \\
Magazine $^{\mathrm{b}}$ & 40 & 26 & 13.82 & $<0.001$ & 1.84 & 1.33 & 2.56 \\
Doctor $^{\mathrm{a}}$ & 44 & 52 & 5.84 & 0.016 & 0.69 & 0.51 & 0.93 \\
Sexual-health workers $^{\mathrm{c}}$ & 69 & 61 & 5.76 & 0.016 & 1.47 & 1.07 & 2.01 \\
\hline
\end{tabular}

OR: odds ratio. $\mathrm{Cl}_{.95}$ : 95\% confidence interval. LL: lower limit. UL: upper limit.

Note: ${ }^{a}$ Ability to talk to. ${ }^{\mathrm{b}}$ Preferred for more information. ${ }^{\mathrm{C}}$ Preferred for being taught by. 
Table 3. Logistic regression analysis of preference for sources with faith of school as a predictor (mainstream schools)

\begin{tabular}{|c|c|c|c|c|c|c|c|}
\hline \multirow[b]{2}{*}{ Source } & \multicolumn{2}{|c|}{ Percentage } & \multirow[b]{2}{*}{$\chi^{2}(1)$} & \multirow[b]{2}{*}{$p$} & \multirow[b]{2}{*}{ OR } & \multicolumn{2}{|c|}{$\mathrm{Cl}_{.95}$} \\
\hline & Catholic & $\begin{array}{l}\text { Church of } \\
\text { England }\end{array}$ & & & & LL & UL \\
\hline Sexual-health workers ${ }^{a}$ & 78 & 57 & 34.90 & $<0.001$ & 0.37 & 0.26 & 0.52 \\
\hline $\begin{array}{l}\text { Quality of sex- } \\
\text { education intervention }\end{array}$ & 57 & 46 & 7.50 & 0.006 & 0.66 & 0.48 & 0.89 \\
\hline Adolescents $^{\mathrm{a}}$ & 16 & 24 & 6.37 & 0.012 & 1.63 & 1.11 & 2.40 \\
\hline Web site ${ }^{c}$ & 40 & 49 & 6.24 & 0.013 & 1.47 & 1.09 & 2.00 \\
\hline Doctor $^{d}$ & 52 & 44 & 4.09 & 0.043 & 0.73 & 0.54 & 0.99 \\
\hline
\end{tabular}

OR: odds ratio. $\mathrm{Cl}_{.95}$ : 95\% confidence interval. LL: lower limit. UL: upper limit.

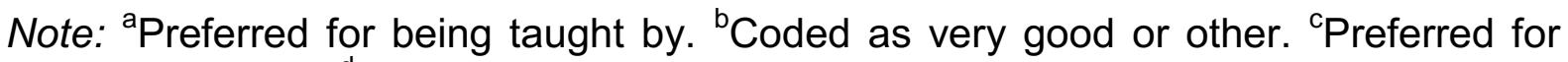
more information. ${ }^{\mathrm{d}}$ Ability to talk to. 
Table 4. Logistic regression analysis of preference for sources with gender as a predictor (special schools)

\begin{tabular}{|c|c|c|c|c|c|c|c|}
\hline \multirow[b]{2}{*}{ Source } & \multicolumn{2}{|c|}{ Percentage } & \multirow[b]{2}{*}{$\chi^{2}(1)$} & \multirow[b]{2}{*}{$p$} & \multirow[b]{2}{*}{ OR } & \multicolumn{2}{|c|}{$\mathrm{Cl}_{.95}$} \\
\hline & Girls & Boys & & & & LL & UL \\
\hline Web site $^{a}$ & 24 & 58 & 6.76 & 0.009 & 0.23 & 0.07 & 0.73 \\
\hline Phone line $^{a}$ & 44 & 15 & 5.96 & 0.015 & 4.40 & 1.28 & 15.15 \\
\hline Friends $^{b}$ & 44 & 18 & 4.58 & 0.032 & 3.54 & 1.08 & 11.57 \\
\hline
\end{tabular}

OR: odds ratio. $\mathrm{Cl}_{.95}$ : 95\% confidence interval. LL: lower limit. UL: upper limit. Note: ${ }^{a}$ Preferred for more information. ${ }^{b}$ Ability to talk to. 
Table 5. Logistic regression analysis of preference for sources with school type as a predictor (all schools)

\begin{tabular}{|c|c|c|c|c|c|c|c|}
\hline \multirow[b]{2}{*}{ Source } & \multicolumn{2}{|c|}{ Percentage } & \multirow[b]{2}{*}{$\chi^{2}(1)$} & \multirow[b]{2}{*}{$p$} & \multirow[b]{2}{*}{ OR } & \multicolumn{2}{|c|}{$\mathrm{Cl}_{.95}$} \\
\hline & Mainstream & Special & & & & LL & UL \\
\hline Sexual-health workers ${ }^{a}$ & 66 & 36 & 19.09 & $<0.001$ & 3.36 & 1.93 & 5.87 \\
\hline Parents $^{a}$ & 14 & 36 & 16.91 & $<0.001$ & 0.28 & 0.16 & 0.49 \\
\hline Friends ${ }^{\mathrm{b}}$ & 57 & 29 & 16.16 & $<0.001$ & 3.13 & 1.74 & 5.62 \\
\hline Home $^{c}$ & 21 & 38 & 8.24 & 0.004 & 0.43 & 0.24 & 0.75 \\
\hline School nurse ${ }^{a}$ & 15 & 31 & 8.06 & 0.005 & 0.40 & 0.22 & 0.73 \\
\hline Magazine $^{c}$ & 34 & 17 & 7.54 & 0.006 & 2.47 & 1.23 & 4.96 \\
\hline
\end{tabular}

OR: odds ratio. $\mathrm{Cl}_{.95}$ : $95 \%$ confidence interval. LL: lower limit. UL: upper limit.

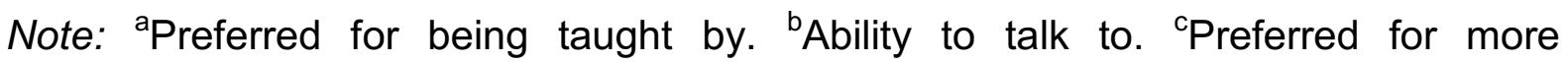
information. 